atomic weight to 207.19 and density to 11.34 . Similarly "neo" lead, or freshly created lead, formed by radio-active disintegration, would very slowly increase its mass and eons hence have a higher atomic weight and density.

All other elements should be subject to an increase in mass and it could therefore be predicted that $e . g$. , helium of the atmosphere and of minerals will have an "atomic weight" which is .0214 higher than the atomic weight of helium from radioactive disintegration, that is: there should be an "old" or "common" helium with atomic weight of about 3.94, and a "neo" helium of atomic weight 3.92 .

There is at present no evidence for the fallacy of such a speculation, in fact it seems to be supported by certain widely different phenomena to wit:

(a) Radio-activity.-The difference in the atomic weights of "leads" is explained in a plausible way. It is a safe guess to predict that common lead can not be separated. While a mixture of common and radioactive lead might be separated by fractional diffusion.

(b) Astro-physics.-The stellar evolution, revealed by characteristic types of stellar and nebular spectra, points to a close relationship between the constituents of celestial bodies and the periodic law. This indicates an evolution of chemical elements following the periodic system.

(c) Geo-chemistry.-Here the remarkable fact is shown that over 99 per cent. of the elements upon the known earth surface are those of low atomic weight. These elements occupy neighboring places in the periodic system which seem to indicate that the earth has reached a certain definite stage of evolution, practically halfway of the third period in the periodic system.

(d) Bio-chemistry.-From 96-99.5 per cent. of all living matter is composed of the four elements $\mathrm{C}, \mathrm{H}, \mathrm{O}$ and $\mathrm{N}$, all four being neighbors in the periodic system. The other elements essential to life are closely grouped around.

Therefore is it not possible that biological evolution follows stellar evolution, and stellar evolution follows chemical evolution? If stellar and chemical evolution go hand in hand; then the physical, chemical and biological condition of a celestial body will depend entirely upon its age.

Where is the evidence that the elements of to-day : were eons ago the same substances and preserved their properties unaltered? It is possible that the electrons of the atom might very slowly lessen their orbital motion and thereby attract and hold additional free electrons thus increasing in valency and mass. Thus, e. g., a sodium-atom by catching an electron would increase in its valency and become a magnesium-atom. Magnesium in time transmutates into aluminum and so on.

Just as the astronomical experience of mankind is recognized to be a snapshot of the universe, so all chemical and physical knowledge of man is the limited inventory, taken during an infinitesimal fraction of eternity.

INGo W. D. HACKH

$$
\begin{aligned}
& \text { Berkelex, CAL., } \\
& \text { January 22, } 1919
\end{aligned}
$$

\section{DESICCATED VEGETABLES}

An admirable exposition of the anhydrous food industry has recently appeared in a government bulletin entitled "Relation of Dehydration to Agriculture" and written by Major S. C. Prescott. After reading this paper one can not fail to come to the conclusion that the preparation of dried foodls is destined to become a very important industry. However, before such an industry can yield the maximum return it is essential that the eaters of the dried foods be scientifically assured that desiccated foods possess proper nutritive value. Some such investigations have been made but there is a need for very comprehensive studies.

It is a matter of common knowledge that desiccated vegetables, for example, will assume a form closely approaching that of the fresh vegetable after having been immersed in water for a few hours. This fact is often cited as demonstrating that there has been no alteration in the structure of the vegetable cell during the dehydration process. However, if we 
remove the swollen vegetable from the water and permit it to remain at room temperature for twenty-four to thirty-six hours it will return to its anhydrous state. This phenomenon, it seems to me, stamps the anhydrous product as an entirely different product, structurally, from the fresh product, but does not necessarily indicate any lowering in food value. In other words a fresh vegetable holds its water much more tenaciously than does a dehydrated vegetable which has had its water removed and has subsequently been immersed in water and made to assume a form closely approximating that of the fresh vegetable. Is the failure of the anhydrous vegetable to retain its water to the same degree as the fresh vegetable due to the fact that the drying has brought about some change in the colloids of the vegetable cells which lowers their power to hold water? Or does the removal of salts through the "soaking" process lower the imbibition power of the colloids? Or is there some other answer? An explanation from our friends the physical chemists would be in order.

The above phenomenon was called to my attention by Mr. Charles Denby of the War Trade Board and Mr. Daniel Moreau Barringer both of whom are much interested in the general problem of food desiccation.

\section{Jefferson Medical College,}

Phillp B. Hawk

Philadelphia

\section{NONSILVERABLE CONTAINERS FOR SILVERING MIRRORS}

To THE EdITor of SoIEnce: In connection with recent contributions to your columns under the title "Nonsilverable Containers for Silvering Mirrors" the writer may be permitted to record an observation made several years ago. 'This was that silvering solution could not be made to deposit on black amorphous selenium, although it coated the walls of the glass vessel in which the piece of selenium was placed. The converse of this experiment, namely silvering a piece of glass in a vessel lined with selenium, was not tried, but would appear to offer the solution of the problem of a container that will not attract silver.

Herbert E. Ives
AD REM OF A HISTORY OF SCIENCES IN THE UNITED STATES

Is the long years of my labors in scientific reference work I found myself greatly hampered by the lack of an available source history of the different branches of sciences, especially of the exact sciences, in the United States. There are three important contributions in this field, all written by the late George Brown Goode: "The Origin of the National Scientific and Educational Institutions of the United States," 1890; "The Beginnings of Natural History in America," 1886; and "The Beginnings of American Science," 1887. Nobody who is acquainted with these papers can withhold his admiration for Mr. Goode's painstaking work, but after all they are only stepping stones and cover only a limited period, and serve merely, as it was contemplated by Mr. Goode, as an outline.

The more interested I became in the matter the more I found myself impressed by the idea to see that this great lacuna should be filled. The best channel through which to accomplish this seemed to me to lay the matter before the American Association for the Advancement of Science, have it discussed there in its entirety, and if possible undertaken by the association or under the auspices of the association. The outbreak of the world war made it seem advisable to me to postpone my plan. A year or two ago I broached the subject with Dr. L. O. Howard, the permanent secretary of the association, who fell in with the idea and expressed his willingness to submit my suggestion to the committee on policy, whenever I should be ready to present it in concrete form. Last October when the end of the war seemed to be only a matter of months I thought the time had come for action. Therefore, I addressed on October 25th the following communication to Dr. L. O. Howard:

Dear Sir:

There is as yet no history of sciences in the United States showing the important and farreaching partieipation of our men of science in the general development of science. Now seems to be the proper time to seriously consider such an undertaking, as the great world war has changed and 